\title{
Fungicides against mildew case of Potato (Solanum tuberosum .L.) from the Triffa plain, irrigated area of Moulouya
}

\author{
Karima Alaoui ${ }^{1 *}$, Zouheir Chafik $^{2}$, and Ez-zahra Kharmach $^{1}$ \\ ${ }^{1}$ Faculty of Sciences, Laboratory of Biochemistry and Biotechnology, 60000, Morocco \\ ${ }^{2}$ Faculty of Sciences, Laboratory of Plant and Microorganism Biology 60000, Morocco
}

\begin{abstract}
The 2016-2017 agricultural season was devoted to prospecting in different farms in the Triffa Plain. Mildew is present in almost all areas of the plain, given the favourable climatic conditions. Around $95 \%$ of the potato cultivated areas in the irrigated area of Moulouya are concentrated only in the Triffa plain, from which 51 plots have been identified. This survey showed that a total of 34 plots ( 476 hectares covering about $22 \%$ of the total area under potato cultivation) were attacked differently by the late blight, and the area managed by the Agricultural Valorization Center (AVC 108) showed the highest attack degree .Preventive control is the most used measure by farmers to protect their crops from attacks by this pathogenic fungus. More than $89 \%$ of farmers apply chemicals with health protection measures that are often insufficient or totally absent (77\% of farmers apply 4 to 6 fungal treatments per cycle). However, the nonrational use of these chemicals revealed serious problems that are harmful to the various environment components, namely fauna and especially human beings' health. The results obtained in this study recommend the use of rather organic and ecological treatments that are favourable for the preservation of human health and guarantee a sustainable and healthy agricultural production.
\end{abstract}

\section{Introduction}

The Potato (Solanumtuberosum. L.) is a perennial tuberous solanaceous plant native to South America. This vegetable is the fourth largest food crop in the world; it is the most consumed in the world due to its high nutritional value and is gradually becoming a staple food in many countries, with more than one billion consumers worldwide [19]. The potato was introduced in Morocco in the $19^{\text {th }}$ century and has bacome increasingly important for a balanced diet. The demand for this crop then increased and therefore became cultivable in practically all regions of Morocco [13]. The area occupied by market gardening in Morocco varies each year between 180 and 200,000 ha, of which 50 to 60,000 ha are sown with potatoes, or $25 \%$ of the total market gardening area [14]. In 2016, the area under vegetable crops was 218,000 ha including 59,400 ha of potatoes [15]. In the irrigated area of Moulouya, $95 \%$ of the cultivated area with potatoes is concentrated in the Triffa plain. This is mainly due to the quality of the soil, favourable climate, existence of the water table for supplementary irrigation and good control of the crop by the majority of farmers. This crop is the main vegetable species grown in the region with an average area of about 5000 ha of which 4000 to 4500 ha are for seasonal potatoes [16].

However, the crop in the region is subject to various attacks from the pest's diseases and weeds. Since antiquity, people have tried to control these bioaggressors and protect their crops using various control methods that remained ineffective until the appearance of chemical products. It was in the year 1940 that the first synthetic pesticides appeared on the market, with very positive results in terms of increasing agricultural yields [9]. Despite the benefits reaped from pesticides, they present inevitable risks to human health, wildlife and the environment. The world's consumption of pesticides reached 3013.97 million $\mathrm{kg}$ in 2014 [17]. The country with the highest consumption of phytosanitary products in the world is China, followed by Argentina and Mexico [17]. The objective of this study was to conduct surveys among farmers in the region in order to collect as much information as possible on the chemical control of potatoes and specifically that of late blight, and to show the effect of chemical products on various components of the environment.

\section{Materials and methods}

\subsection{Presentation of the area of study}

The present study involved the Triffa plain located in the Eastern Morocco, at the Northeastern extremity of the contry, bordering the Mediterranian Sea and the Morocan-Algerian borders. It has a Mediterranean-type

Corresponding author: karima.alaoui2@gmail.com 
climate, semi-arid in the north and arid in the south. The average annual rainfall is variable and is characterized by a spatiotemporal irregularity. Rainfall is lower in the order of 150 to $300 \mathrm{~mm} /$ year $[10,11]$

\subsection{Farm Selection and Surveys}

This choice was made with the help of lists of farmers obtained from the plant production service at ORMVAM (regional office for the agricultural development of the Moulouya), as well as the potato producers' association. The lists contain the names of the farmers in each AVC, the address, telephone number and the area cultivated with potatoes. The soil and climate conditions in each AVC vary little or very gradually.

The farms surveyed in the 9 AVC, of the Triffa plain were chosen at random and according to the availability of means of transport, farmer's agreement and availability of reliable information

\subsection{Conducting Surveys}

The year 2016 was devoted to surveys. These were conducted in the field with farmers in 51 potato farms from January to May. During site visits to the farms, interviews and discussions were conducted with farmers using the survey questioning. Very precise surveys were carried out on the phytosanitary treatments that the crop received, which include frequency, dose and type. The survey lasted about 40 minutes on average with each farmer.

\section{Results and discussions}

\subsection{Importance of the culture in the plain}

The area occupied by potato's farm in the Moulouya perimeter in 2016 was 2558 ha, of which 2125 ha were concentrated in Triffa's plain.

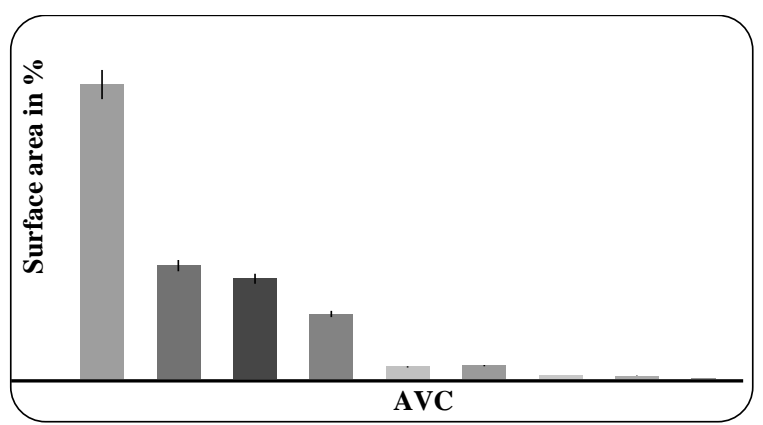

Fig. 1. Distribution in percentage of the potato area in different AVCs of Triffa's plain

Figure 1 shows the distribution of potato area in different CVAs in relation to the total area in the plain. The Madagh subdivision (AVC 108, AVC 107, AVC 106, AVC 103, AVC 109, and AVC 101) had 2102 ha and alone accounted for $98.92 \%$ of the total area. The large area was recorded in the AVC 108 action zone with $44.24 \%$ followed by the AVC 107 action zone with 17.04\%. Boughriba's subdivision (AVC 102, AVC 105, and AVC 104) had only 23 ha or $1.08 \%$ of the total spring potato area.

\subsection{Farm selection and surveys}

Out of a total area of 2125 ha sown to potato in Triffa's plain, the area surveyed was 526 ha distributed as shown in Table 1.

The areas surveyed were proportionally related to the total area of each AVC.

Table 1: Distribution of surveys relative to total potato average in each AVC

\begin{tabular}{|c|c|c|c|}
\hline AVC & $\begin{array}{l}\text { Total area of } \\
\text { potato in ha }\end{array}$ & $\begin{array}{c}\text { Surveyed } \\
\text { plots }\end{array}$ & $\begin{array}{c}\text { Area surveyed in } \\
\text { ha }\end{array}$ \\
\hline 108 & 940 & 20 & 160 \\
\hline 107 & 362 & 8 & 90 \\
\hline 106 & 320 & 7 & 52 \\
\hline 101 & 220 & 3 & 99 \\
\hline 103 & 230 & 5 & 92 \\
\hline 109 & 30 & 2 & 17 \\
\hline 102 & 11 & 2 & 6 \\
\hline 105 & 10 & 2 & 6 \\
\hline 104 & 2 & 2 & 4 \\
\hline Total & 2125 & 51 & 526 \\
\hline \multicolumn{4}{|c|}{$\begin{array}{l}\text { AVC: Agricultural Valorisation Center } \\
\text { AVC108 Ain Chebbak, AVC } 107 \text { Ain Regada, AVC } 106 \text { Laatamna, } \\
\text { AVC } 101 \text { Madagh, AVC } 103 \text { Slimania, AVC } 109 \text { Ahfir, AVC } 102 \\
\text { Boughriba, AVC } 105 \text { Tzayest, and AVC } 104 \text { Chouihiya }\end{array}$} \\
\hline
\end{tabular}

\subsection{Importance of the disease in the plain}

Every crop year, potato growers in Triffa's plain said that spring rains, excessive relative humidity and favourable temperature were the factors for the development of late blight. The severity of the disease had been medium to high during this period. The first symptoms of the disease were recorded around midFebruary with the first curative treatments.

All the plots surveyed in 2016 in all regions of the plain were attacked by mildew, and the high humidity and mild temperatures that had persisted since the beginning of the season had caused a significant spread of the fungus.

The degree of attack differs from one area to another and depended on the variety, date of planting, quality of the seed used, and crop maintenance. The AVC 108 had a very high severity, given its proximity to the Mediterranean coastline, the number of treatments in this AVC was between seven and eight /cycle. Out of 51 plots surveyed, 34 plots were attacked by late blight.

The total area attacked by late blight in the Moulouya perimeter in the year 2016-2017 amounted to 476 ha, or around $22 \%$ of the total area sown to potatoes. The most 
attacked area was located in the action zone of AVC 108 and amounted to about $7 \%$ of the total area. The action zones of AVC 101, 103 and 107 had, respectively, an attack area of $4.66 \%, 4.33 \%$ and $3.67 \%$ of the total area.

Table 2. Distribution of plots and areas attacked by mildew in 2016.

\begin{tabular}{|c|c|c|c|c|}
\hline AVC & $\begin{array}{c}\text { Attacked } \\
\text { plots }\end{array}$ & $\begin{array}{c}\text { Attacked } \\
\text { areas in ha }\end{array}$ & $\begin{array}{c}\text { \%/ to } \\
\text { zone }\end{array}$ & $\begin{array}{c}\text { \% to } \\
\text { Périmètre }\end{array}$ \\
\hline 108 & 14 & 140 & 14.89 & 6.59 \\
\hline 107 & 6 & 78 & 21.55 & 3.67 \\
\hline 106 & 4 & 49 & 15.31 & 2.31 \\
\hline 101 & 3 & 99 & 31.6 & 4.66 \\
\hline 103 & 1 & 92 & 40 & 4.33 \\
\hline 109 & 2 & 5 & 10 & 0.24 \\
\hline 102 & 2 & 6 & 54.55 & 0.28 \\
\hline 105 & 1 & 5 & 50 & 0.24 \\
\hline 104 & 1 & 2 & 100 & 0.09 \\
\hline Total & $\mathbf{3 4}$ & $\mathbf{4 7 6}$ & $\mathbf{2 2 . 4}$ & $\mathbf{2 2 . 4}$ \\
\hline
\end{tabular}

\subsection{Phytosanitary protection of potatoes and their impact in the region}

\subsubsection{Control of mildew}

The chemical control was the most used by the farmers of the region because of its permanent availability in the market, its low cost and its very positive results, the potato of the region received on average between 6 to 8 treatments during its cycle. Figures 2 and 3 show the frequency of fungicide use for late blight in each AVC.

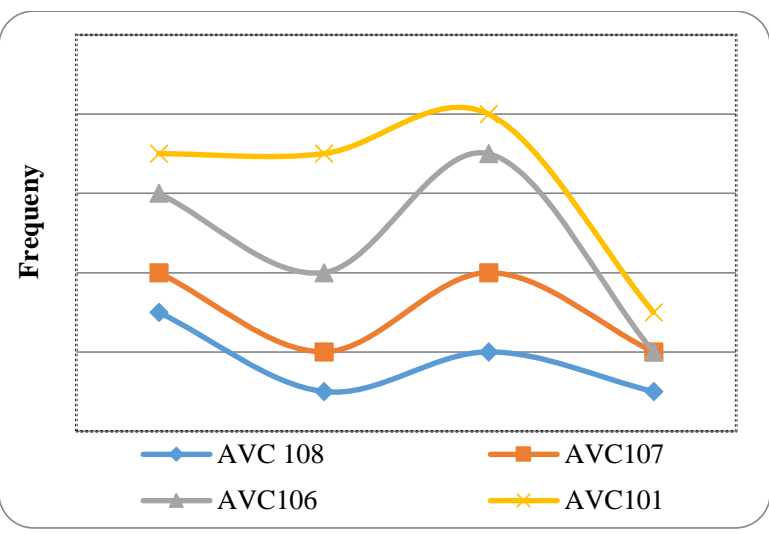

Fig. 2. Average frequencies of fungicides used for late blight, control over a full potato cycle in different AVC.

The action zone 108 in view of their proximity to the coastline is most attacked by late blight and therefore the average frequency of control was high and received7 to 8 treatments per cycle, followed by AVC 106 and 101 respectively 7 and 6 treatments on average. In general, farmers in the region are turning to preventive treatments to protect their crops from attacks by the fungus; these products are contact and copper-based.
However, their excessive use for fear of attack caused serious environmental problems.

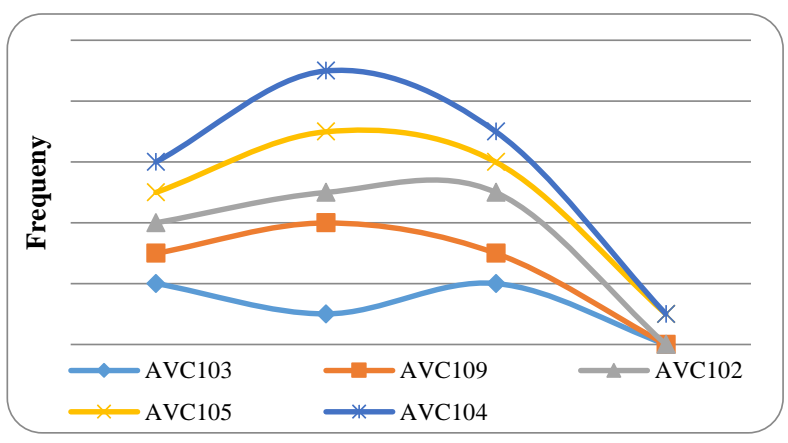

Fig. 3. Average frequencies of fungicides used for late blight, control over a full potato cycle in different AVC.

The Oued of Moulouya was particularly affected by these pollution problems due to the continued development of the industrial and agricultural sectors [1].

A study on water quality in the Oued of Moulouya showed that agriculture contributed to water pollution through the excessive use of nitrogen and phosphate fertilizers, pesticides, herbicides and fungicides [2]. During their use, the pesticides losses can exceed $2 \%$ of the amount applied $[3,4]$.

Their dispersed molecules are often found in different parts of the environment (water, air, soil...) [6, 7]. The volatilization process remained the most important factor, thus, Taylor and Spencer have shown that losses of pesticides through this process can reach 80 to $90 \%$ of the applied amount [5].

\subsubsection{Different treatments}

Figure 4 shows the average frequency of the different treatments that the crop received before and after planting's time. Indeed, the latter depended on the climatic conditions and the persistence of the products. Background manure was applied before the crop was planted, with $97 \%$ of the farms surveyed using the NPK formula, - N: 40 to $50 \mathrm{U}-\mathrm{P}_{2} \mathrm{O}_{5}: 90$ to $160 \mathrm{U}-\mathrm{K}_{2} \mathrm{O}: 100$ to $220 \mathrm{U}$. Cover fertilization mainly concerned nitrogenous fertilizers, most often applied in two or three applications.

The dose was 100 to $150 \mathrm{U}$ in the form of $33.5 \%$ ammonium nitrate, and $100 \%$ of the farmers surveyed did not exceed three applications per cycle.

Chemical mixing was very essential to effectively control weeds. The most commonly used herbicide in the region was METRIBUZINE (Sencor 70) at a rate of 0.5 to $1 \mathrm{~kg} / \mathrm{ha}$. Herbicides were among the molecules most frequently detected in water, a significant contamination can be generated by very low losses of pesticides: a leak of less than 1/1000e of the mass of herbicide spread on a plot can be enough to contaminate the water flowing over the threshold of potability [12]. 


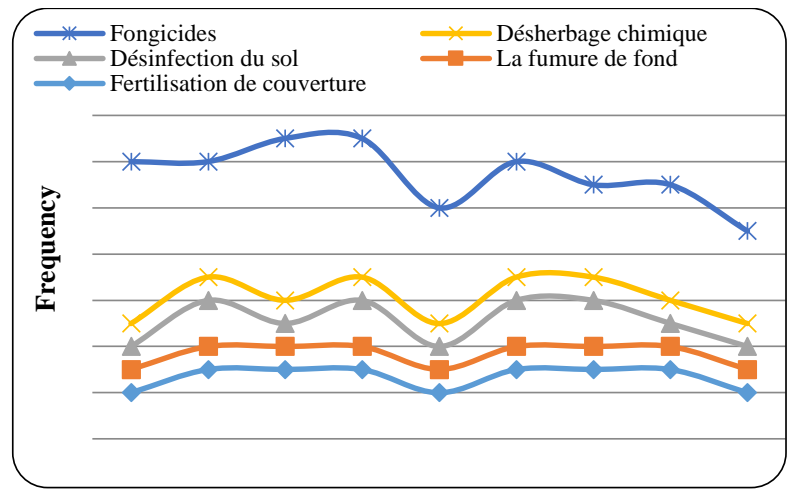

Fig. 4. Average frequencies of different treatments used on potato during a full cycle in different AVC

Finally, soil disinfection was also essential to control the parasites that infected the land of Moulouya, $87 \%$ of farmers surveyed use the product Mocap with a frequency that did not exceed 2 apports per cycle, the active matter was Ethoprophosas part of the family of organophosphorus, at a rate of 4 to $20 \mathrm{~kg} / \mathrm{ha}$, with a frequency that did not exceed 2 treatments per cycle. Farmers used it at the time of planting and introduced it into the soil at a depth of 7 to $15 \mathrm{~cm}$.

Ethoprophosas is very harmful, and it was no longer authorized in France in 2019 [8]. A bad incorporation of the product in the soil caused the death of animals and birds through food. It was the lack of selectivity of pesticides towards their target that caused most of the harmful effects on the environment.

Animals absorbed pesticides through food or feed water, through the air they breathed or through their skin or cuticle. Consequently, it caused the death of fish, mammals or birds and therefore they presented various degrees of danger to human health and ecosystems with short or long-term impact [12].

\section{Conclusion}

Moulouya's Farmers extensively used chemicals to control pests, the most commonly used pesticides were insecticides, fungicides and herbicides. Each family of pesticides contained several types, and the farmer must choose the appropriate pesticide according to the nature of the plants, pests and diseases.

Pesticides are useful for plant protection and increasing production volume, but their risks as chemicals outweigh their usefulness; their unsound use and their use with often inadequate or no protective measures cause environmental problems for wildlife and human health as well.

\section{References}

1. M. Makhoukh, M. Sbaa, A. Berrahou, M. van. Clooster, Larhyss J, 149-169 (2011)

2. My H. Bekri, A. El Hmaidi, H. Jaddi, H. Ousmana, Z. Kasse, ElFaleh, A. Essahlaoui, A. ElOuali, Eur. Sci. J, 16, 9 (2020)
3. M. Robert, Bulle. Acad. Natel. Med, 1, 21-42 (1997)

4. R. A. Leonard, in Soil Science Society of America Book. Madison (1990)

5. A.W. Taylor, W. F Spencer, In Pesticides in the soil environment. Soil Science Society of America Book Series, $\mathrm{n}^{\circ}$ 2, Madison, WI, USA, 213-269 (1990)

6. C.T. Schomburg, D.E. Glotfelty, Envir. Sci, Tech, Califonia, 25, 155-160 (1991)

7. D.J. Gregor, W.D. Gummer, Envir. Sci. Tech, 23, 561-565 (1989)

8. P. Larroude, P. Taupin, arvalis-Institut du vegetal (2012)

9. V. Rizzati, O. Briand, H. Guillou, L. GametPayrastre, Chemico-Biological Interactions, 254, 231-246 (2016)

10. R. Negre, Travaux de l'Institut Scientifique Chérifien, série botanique, 13, 386 (1959)

11. T. Ionesco, Les Cahiers de la Recherche Agronomique, 19, 1-69 (1965)

12. O. Saadane, Faculté de Medecine et Pharmacie, Rabat Thèse $\mathrm{N}^{\circ} 127$ (2018)

13. Anonyme. Bull. de transfert de technologie. Institut Agronomique et Vétérinaire Hassan II, Programme National de Transfert de Technologie en Agriculture CNTTA (1999)

14. MAPM, site de ministèred'agriculture et de pèche maritimes, https://www.agriculture.gov.ma/pages/statistiquesagricoles, consulté le 11/12/2019 (2014)

15. MAPM, site de ministère d'agriculture et de pèche maritimes,

https://www.agriculture.gov.ma/pages/statistiquesagricoles, consulté le 17/01/2021 (2017).

16. Anonyme, Rapport de situation. ORMVAM (2016)

17. FAOstat, Agence de statistique de l'organisation pour l'alimentationet agriculture FAO, consulté le 17/01/2021. (2018)

18. FAO 2010, Agencede Statistiquede l'Organisationpour l'AlimentationetAgriculture FAO, Statistiquesmondiale de pomme de terre. (www.fao.org/faostat), consulté le 17/03/2017 